\title{
Microscopic Investigation of As Built and Hot Isostatic Pressed Hastelloy X Processed by Selective Laser Melting
}

\author{
Saeid Pourbabak ${ }^{\mathrm{a}, \mathrm{b}}$, Maria L. Montero-Sistiaga ${ }^{\mathrm{b}, \mathrm{c}}$, Dominique Schryvers ${ }^{\mathrm{a}}$, Jan Van \\ Humbeeck $^{\mathrm{b}}$, Kim Vanmeensel ${ }^{\mathrm{b}}$ \\ ${ }^{a}$ EMAT, University of Antwerp, Groenenborgerlaan 171, B-2020 Antwerp, Belgium \\ ${ }^{\mathrm{b}}$ MTM, Department of Materials Engineering, University of Leuven, Kasteelpark \\ Arenberg 44, B-3001 Leuven, Belgium \\ ${ }^{c}$ ENGIE-Laborelec, Rodestraat 125, B-1630 Linkebeek, Belgium
}

Microstructural characteristics of Hastelloy $\mathrm{X}$ produced by Selective Laser Melting have been investigated by various microscopic techniques in the as built (AB) condition and after hot isostatic pressing (HIP). At sub-grain level the AB material consists of columnar high density dislocation cells while the HIP sample consists of columnar sub-grains with lower dislocation density that originate from the original dislocation cells, contradicting existing models. The sub-grains contain nanoscale precipitates enriched in $\mathrm{Al}, \mathrm{Ti}, \mathrm{Cr}$ and $\mathrm{O}$, located at sub-grain boundaries in the $\mathrm{AB}$ condition and within the grains after HIP. At some grain boundaries, micrometer sized chromium carbides are detected after HIP. Micro hardness within the grains was found to decrease after HIP, which was attributed to the decrease in dislocation density due to recovery annealing.

Keywords: superalloy, dislocation cell, sub-grain growth, precipitation, selective laser melting, additive manufacturing 


\section{Introduction}

Selective Laser Melting (SLM) is a fast and effective Additive Manufacturing (AM) method to produce functional metallic components with complex geometries. The high cooling rate obtained during the process results in very fine microstructures, yielding microstructural features different from those observed in materials produced with conventional processing techniques. As mechanical properties are strongly affected by the material's microstructure, it is essential to first understand the relationship between microstructure and processing in order to predict its impact on the resulting mechanical properties [1-5].

Several authors have reported on the microstructure of SLM produced nickel-based superalloys such as IN718 [6,7], IN738LC [8], In939 [1] etc. Most of the nickel alloys present elongated columnar grains along the SLM building direction that grow epitaxially across several build layers [1,7,9]. At a sub-grain scale, cell-shaped structures [9-11] with low-angle boundaries have been observed [1]. At the cell boundaries, Divya et al. found high dislocation densities in SLM processed CM247LC [9] while Wang et al. [12] reported a higher dislocation density in regions where precipitates were present in SLM processed CM247LC. These dislocations defined the boundaries between cells which were approximately $700 \mathrm{~nm}$ wide and of virtually identical orientation. Using X-ray mapping they found $\mathrm{Hf}, \mathrm{W}, \mathrm{Ti}$ and/or Ta-rich precipitates containing $\mathrm{C}$ and/or $\mathrm{O}$ along parts of the cell boundaries. In 316L stainless steel, similar features were observed by Liu et al. [13]. They reported on the presence of dislocation networks inside individual grains with dislocations concentrated at the walls of columnar cells in 316LSS, similar as the ones found in nickel alloys. Apart from slight orientation differences between neighboring dislocation cells, the cells are aligned along the direction of the temperature gradient that was imposed during the solidification process. Segregation of $\mathrm{Mo}, \mathrm{Mn}, \mathrm{Cr}$ and $\mathrm{Ni}$ towards the dislocation cell walls was observed as well. Post-processing heat treatments can further influence the microstructure evolution, including the formation of precipitates, in nickel-based superalloys. Amato et al. [7] observed recrystallized regions after heat treating IN718 at $1163{ }^{\circ} \mathrm{C}$. Kanagarajah et al. [1] also found recrystallized grains after two step aging of IN939. In the case of IN738LC, precipitation of $\mathrm{MC}$ and $\mathrm{M}_{23} \mathrm{C}_{6}$ carbides was found at the grain boundaries after a heat treatment at $1170{ }^{\circ} \mathrm{C}$ [14].

Hastelloy X is a solid solution strengthened FCC nickel-based superalloy with $\mathrm{Cr}$, Fe and Mo as the main alloying elements together with $\mathrm{Co}$ and $\mathrm{W}$ at a lower concentration with excellent resistance to corrosion and oxidation [15]. Hastelloy $\mathrm{X}$ is widely used in gas turbine engines for combustion-zone components and petrochemical applications thanks to its excellent resistance to harsh environments and strength at elevated temperatures [15]. The microstructure of Hastelloy X after SLM has been reported on in several works [4,5,16,17]. In the as built state, columnar grains aligned along the building direction with the length of 
the grains exceeding the depth of one molten pool have been observed $[5,16]$. These columnar grains show internal structures referred to as fine parallel dendrites with a diameter of $~ 0.5 \mu \mathrm{m}$ [16]. Marchese et al. performed a detailed study on AB samples including the precipitates found in between the substructures, which they classified mainly as Mo6 $\mathrm{C}$. They propose that the carbides were formed during solidification and after several thermal cycles during production [17]. After hot isostatic pressing Tomus et al. [16] identified fine spherically shaped Mo-rich carbides of type $\mathrm{M}_{\mathrm{x}} \mathrm{C}_{\mathrm{y}}$ with average sizes below $100 \mathrm{~nm}$. This type of carbides are also found in commercial wrought Hastelloy X. Zhao et al. [18] reported on the formation of $\mathrm{M}_{6} \mathrm{C}$ at twin boundaries and $\mathrm{M}_{6} \mathrm{C}, \mathrm{M}_{23} \mathrm{C}_{6}, \sigma$-phase, and $\mu$-phase at grain boundaries in heat-treated SLM materials. On the other hand, after HIP, the number of single dislocations is strongly reduced and dislocations arrange themselves in low angle sub-grain boundaries [16].

In the present work, Optical, Scanning Electron and Transmission Electron Microscopy (STEM) was performed in order to unravel the microstructure of Hastelloy $\mathrm{X}$ from nano to macro scale and to understand the evolution of the microstructure after SLM and post HIP treatment. A fundamental understanding of the microstructure evolution is required to be able to interpret the material behavior, not only during quasi-static loading conditions, but especially during high temperature creep and fatigue loading.

\section{Material and methods}

An SLM280HL machine from SLM Solutions (Lübeck, Germany) was employed to build 1 $\mathrm{cm}^{3}$ cubes of Hastelloy X. A laser power of $400 \mathrm{~W}$ was used with an applied laser energy density of $42 \mathrm{~J} / \mathrm{mm}^{3}$, resulting in parts with a relative density of $99.9 \%$ (a powder pycnometry based theoretical density of $8.39 \mathrm{~g} / \mathrm{cm}^{3}$ was used). The base-plate was pre-heated at $200{ }^{\circ} \mathrm{C}$. Some samples were post HIPed at $1155{ }^{\circ} \mathrm{C}$ for 3 hours and furnace cooled at Bodycote (Belgium).

Hastelloy X powder supplied by SLM solutions with particle sizes between 10 and $45 \mu \mathrm{m}$ was used for the SLM process. The composition of the powder measured by the ICPcombustion method is shown in Table 1.

Table 1 Composition of the Hastelloy X powder in weight percent measured by ICP.

\begin{tabular}{llllllllllll}
\hline $\mathbf{N i}$ & $\mathbf{C r}$ & $\mathbf{F e}$ & Mo & Co & W & Si & Mn & C & S & Al & O \\
\hline Bal. & 22.7 & 18.9 & 9.0 & 2.02 & 0.71 & 0.14 & 0.02 & 0.01 & 0.003 & 0.01 & 0.018 \\
\hline
\end{tabular}

A light optical microscope (LOM), Axiocam Leica, was used to observe the microstructure of samples at a macroscopic level. A FEI Nova NanoSEM 450 SEM equipped with an 
electron backscattered diffraction detector (EBSD) was employed for sub-grain characterization. The samples were ground and polished with a $1 \mu \mathrm{m}$ diamond suspension and subsequently etched electrolytically in $10 \%$ oxalic acid solution at $7 \mathrm{~V}$ for $10 \mathrm{~s}$ in order to reveal the microstructure.

A FEI Osiris instrument operating at $200 \mathrm{kV}$ was used for transmission electron microscopy (TEM), high angle annular dark field scanning TEM (HAADF-STEM) and energy-dispersive X-ray spectroscopy (EDX). Automated crystal orientation mapping TEM (ACOM-TEM) was performed on a FEI Tecnai instrument operating at $200 \mathrm{kV}$ and employing the ASTAR ACOM-TEM system by Nanomegas ${ }^{\circledR}$.

Samples were sliced and ground into plates with a thickness of $120 \mu \mathrm{m}$ parallel to the BD direction, after which discs of $3 \mathrm{~mm}$ diameter for TEM were punched. The obtained discs were electropolished with a mixture of $90 \%$ ethanol and $10 \%$ perchloric acid at $-10{ }^{\circ} \mathrm{C}$ using a Struers Tenupol twin-jet electropolishing device.

Micro Vickers hardness was measured using $50 \mathrm{~g}$ load during $30 \mathrm{~s}$. 7 measurements were taken per sample avoiding grain boundaries and hence measuring sub-grain level hardness values.

\section{Results and discussion}

First, LOM, SEM and EBSD were used to analyze the microstructure of AB and HIP samples. The micrographs are shown in Figure 1. In the AB condition, semi cylindrical melt pools, with the long axis perpendicular to the building direction (BD) that are typical for an SLM processed material, are observed in Figure 1 (a). In addition, grains elongated in the building direction with a length up to $100 \mu \mathrm{m}$ and $60 \mu \mathrm{m}$ in width can be seen in Figure 1 (a) as contrast changes and in Figure 1 (b) as outlined by the EBSD pattern. These grains grow epitaxially across several SLM build layers resulting in the creation of a morphological texture. This morphological microstructure has already been reported for Hastelloy X [17,19], IN718 [7] and CM247 [12,20]. Regarding the crystallographic orientation in the EBSD map, no strong texture is observed perpendicular to the BD. At a more microscopic level, when analyzing the microstructure inside the aforementioned grains, a cellular structure is observed, as shown in the SEM inset of Figure 1 (a). Each grain contains cells with varying orientation, depending on the heat gradient during rapid solidification. The inset in Figure 1 (a) differentiates between cells growing along the building direction (depicted with an in-plane arrow) and cross-sectioned cells oriented perpendicular to the building direction (depicted with an outward pointing arrow), depending on the local temperature gradient imposed by the SLM scanning strategy. 
After the HIP process, slightly coarser grains are observed at a macroscopic level when compared with the $\mathrm{AB}$ condition. The melt pool boundaries seen in the $\mathrm{AB}$ condition are no longer noticeable in the LOM image (Figure 1 (c)) and no significant increase or evolution in texture is observed (Figure 1 (d)). At a microscopic level, the cellular sub-grain structure previously observed in the $\mathrm{AB}$ condition is no longer visible by SEM (zoomed inset in Figure $1(\mathrm{c})$ ) and a brighter contrast phase is observed at the grain boundaries.
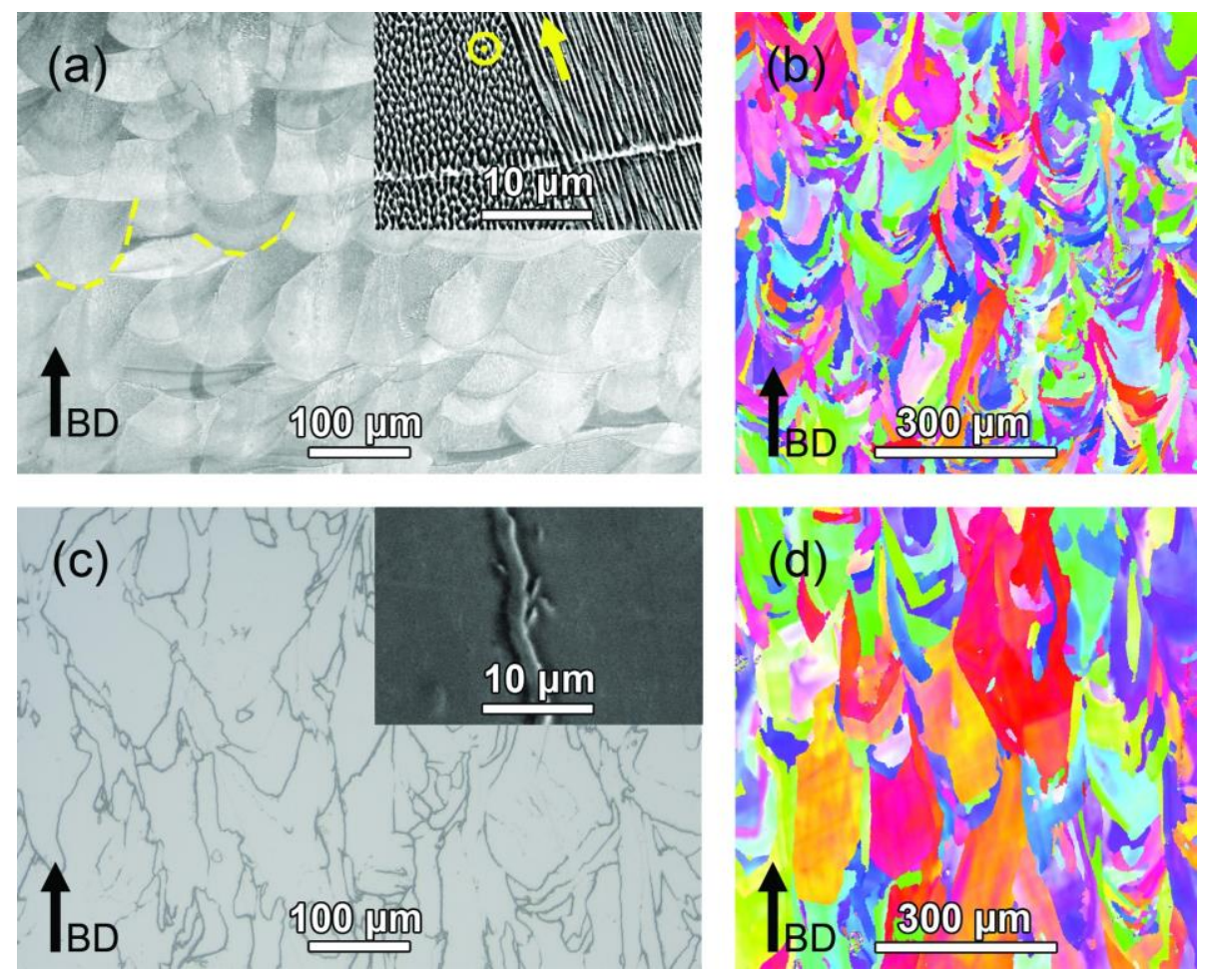

Figure 1 LOM images of (a) AB and (c) HIP sample at a macroscopic level, with a detail of the sub-grain microstructure visualized by SEM and shown as an inset. (b) EBSD image taken parallel to the building direction of the $\mathrm{AB}$ and (d) HIP samples.

\subsection{TEM work on AB sample}

In Figure 2 (a) a representative bright field (BF) TEM image of the AB sample shows two regions with elongated features in the upper-right zone of the image next to more equiaxed features in the lower-left zone of the image. All features have a cellular morphology and correspond to the solidification cells that were observed earlier by SEM and are shown in the inset of Figure 1. A low dislocation density is observed within the core of the cells, while the individual cells are separated from each other by interfaces with a higher dislocation density.

As can be seen in the orientation map, originating from the automated crystal orientation mapping TEM (ACOM-TEM), shown in Figure 2 (b), and obtained from the indicated frame 
in Figure 2 (a), the area consists of two distinct regions with a large $\left(\sim 36 \pm 1^{\circ}\right)$ orientation difference, suggesting the existence of two different grains.

In Figure 2 (c) a detailed picture of another single grain viewed along the equiaxed direction is shown. The corresponding selected area electron diffraction (SAED) pattern (Figure 2 (c) inset) reveals a disordered FCC structure of the matrix with a lattice parameter of $\mathrm{a}=3.58 \AA$, in good agreement with the unit cell parameter of a $\mathrm{NiFe} 20 \mathrm{Cr}$ solid solution [21]. The low and high-density dislocation regions correlate to the cells that were observed by SEM and shown in the inset of Figure 1 (a). A misorientation line profile between a series of adjacent cells is presented in Figure 2 (d) showing steps between the plateaus from $0.2^{\circ}$ to $0.8^{\circ}$. The spikes seen in the profile correspond to pixels located at or near dislocations in the interior of the respective cell. When extending these measurements to an entire grain, misorientations up to $\sim 2 \pm 1^{\circ}$ exist within the low-density dislocation regions, revealing them as dislocation cells separated by dislocation walls.

From the observations in Figure 2 it can be concluded that the shape of the dislocation cells is columnar with a diameter of about $0.5-1 \mu \mathrm{m}$. Depending on the orientation of a grain with respect to the TEM specimen surface, an equiaxed cross-section or a long lateral view of the cells is observed. This confirms the microstructure observed by SEM, where point-like shaped as well as elongated cells of the same magnitude were observed (inset Figure 1 (a)).

The high amount of dislocations found in AB can be explained by the building procedure of the material in which the sample is subjected to repetitive heating and cooling with cooling rates up to $10^{7} \mathrm{~K} / \mathrm{s}$. The plastic work induced during this thermal cycling is partially stored within the cells resulting in an increase in dislocation density. In contrast to other SLM processed materials like 316L [22] or CM247LC [9], no segregation was found at sub-grain boundaries in the present Hastelloy X.

Moreover, as shown in Figure 2 (e), precipitates with sizes ranging from 20 to $50 \mathrm{~nm}$ are observed primarily on dislocation walls, with many located at the triple points of dislocation walls, suggesting pinning and a demobilization of dislocations by precipitates, formed during solidification. In high angle annular dark field scanning TEM (HAADF-STEM) images, the precipitates appear as bright and dark intensities compared to the matrix which indicates different composition or thickness. 

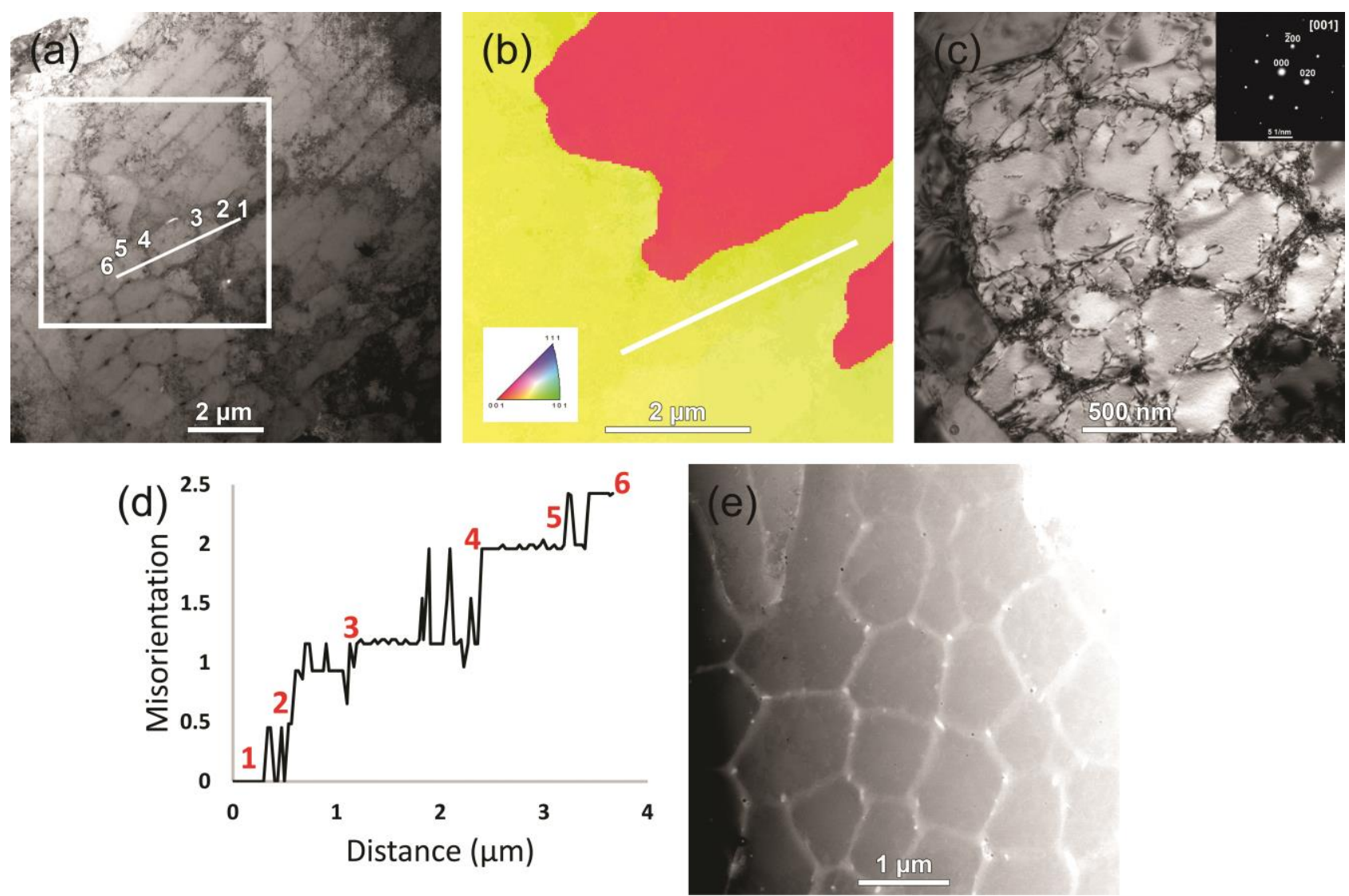

Figure 2 (a) BF-TEM image of equiaxed as well as elongated dislocation cells in two adjacent grains, (b) orientation map of the framed region in (a) showing large and small misorientation between grains and dislocation cells, respectively, (c) typical BF-TEM image of the AB sample taken in [200] two-beam condition showing cells surrounded by dislocation-rich interfaces, (d) misorientation of a series of adjacent cells along the line in (b) and labeled in (a), (e) HAADF-STEM image of bright and dark precipitates on dislocation walls and triple points.

Energy-dispersive X-ray spectroscopy (EDX) elemental maps of a selection of bright and dark precipitates are shown in Figure 3 (a). From these maps it can be concluded that most precipitates appearing dark in this HAADF image are Al-Ti-O-enriched, while most bright ones are Al-Cr-O-enriched. However, EDX measurements performed on several precipitates reveal that precipitates with the same composition may exhibit a different contrast in HAADF-STEM images, which can be due to a) a partial overlap with the matrix, b) different location in the thin foil or c) an occasional internal or coagulated structure of precipitates, as seen in Figure 3 (b-d). Also, in some precipitates, enrichment with other elements such as $\mathrm{Si}$ and Mo was found. In other works of SLM processed Hastelloy X, these precipitates were not observed. Marchese et al. [17,23] found $\mathrm{M}_{6} \mathrm{C}$ type of carbides rich in Mo in the $\mathrm{AB}$ state, 
which were not observed in this work. This can be due to the slight compositional differences between the starting materials.
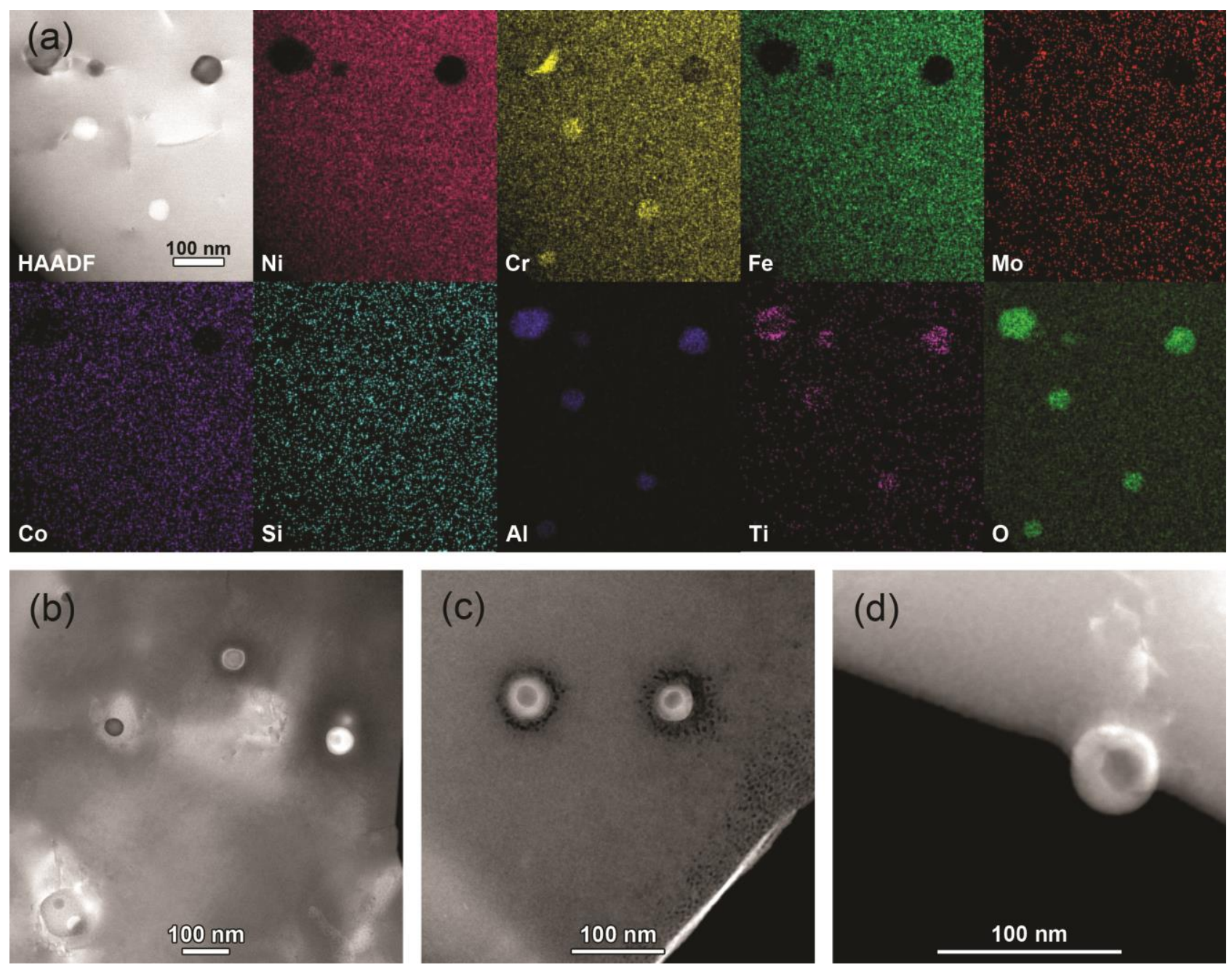

Figure 3 (a) EDX map of some Al-Ti-O and Al-Cr-O-enriched precipitates with dark and bright intensity in the HAADF selection on left, (b)-(d) precipitates with internal structure.

\subsection{TEM work on HIP samples}

In the HIP sample a substantial reduction of the number of dislocations is observed compared to the AB sample, as can be seen in the BF-TEM image of Figure 4 (a) which is taken in the same imaging conditions as Figure 2 (c) in order to obtain comparable results in terms of existing dislocations. It is seen that the dislocation walls of the $\mathrm{AB}$ sample have been transformed into low-angle boundaries in the HIP sample while the dislocation density inside the sub-grains seems to have decreased. ACOM-TEM statistics on the sample show low angle misorientations up to $4 \pm 1^{\circ}$ between the sub-grains, as shown in the orientation map in 
Figure 4 (b) and line trace in Figure 4 (c), which are on average higher than the misorientations between the dislocation cells in the AB sample. This suggests that during HIP cells are not disintegrating, as suggested from the SEM images in Figure 1 (c) inset, but that the dislocation density dropped significantly only to be detected by TEM. No changes in the disordered FCC crystal structure are observed.

These structural changes occur due to annealing recovery of the material during the HIP process. Previously, it was believed that after HIP or after an annealing heat treatment, subgrain cells of Hastelloy X processed by SLM were dissolved into the matrix as they were not visible with SEM $[16,19,23]$. However, in the present work it is shown that these sub-grains remain even after 3 hours of annealing treatment. The merge and/or annihilation of dislocations decreases the number of dislocations, increases the misorientation between subgrains and yields sharper sub-grain boundaries. In addition to the annealing recovery, slight sub-grain coarsening can be observed after the HIP process. Therefore, it can be concluded that after HIP microstructural coarsening takes place at two levels: (1) at the macroscopic level where grains with $>15^{\circ}$ misorientation (Figure $1(\mathrm{~d})$ ) coarsen and (2) at the microscopic level where sub-grain cells coarsen but do not completely disappear (Figure 4 (a)).

In several works, a decrease in yield strength and hardness was found after HIP or annealing treatment of Hastelloy X produced by SLM [4,16]. Micro hardness within the grains was measured for $\mathrm{AB}$ and HIP samples, using a $50 \mathrm{~g}$ load to assure the measurement was performed at the grain level. AB samples exhibit a hardness of $253 \pm 5 \mathrm{HV}$ and HIP presents $202 \pm 14 \mathrm{HV}$, in contrast with $180 \mathrm{HV}$ obtained for conventional annealed Hastelloy X [15]. The values found in literature [16] of AB and HIP samples produced by SLM correspond to the values found in this work. It can be expected that the partial recovery annealing of the dislocations and the slightly increased cell size after HIP is the cause of the softening effect. Nevertheless, it should be mentioned that the remaining dislocation walls after HIP act as sub-grain barriers for other dislocations to move, still providing higher hardness as compared to conventionally produced Hastelloy X. This phenomenon was also observed for 316L produced by SLM followed by HIP treatment, where the yield and hardness were higher than conventional 316L [3,24].

On the other hand, similar precipitates as those earlier observed in the AB sample are present in the HIP sample. However, in the HIP sample, not all precipitates are still preferentially located at the sub-grain boundaries, but also often located next to a sub-grain boundary or even inside a sub-grain, as can be seen in the HAADF image of Figure 4 (d). During HIP at elevated temperature the dislocation walls transform into low-angle grain boundaries during which they can become thinner and some eventually disappear. On the other hand, the precipitates remain at the same location but are not longer connected to a sub-grain boundary. 
In the HIP sample, an additional phase is observed that was not found earlier in the AB sample. The latter phase is located only at a limited amount of grain boundaries. It consists of elongated 100-300 $\mathrm{nm}$ wide particles that often seem to appear in a continuous manner, as shown in the BF-TEM image of Figure 4 (e). EDX measurements, with the elemental maps shown in Figure 4 (f), reveal the composition of this phase as 60.6 at.\% Cr, 16.6 at.\% C, 6.4 at. $\% \mathrm{Mo}, 5.9$ at. $\% \mathrm{Ni}, 5.4$ at.\% $\mathrm{Fe}$ and 5.1 at.\% of other remaining elements. The atomic ratio between $\mathrm{Cr}$ and $\mathrm{C}$ suggests the basic structure to be $\mathrm{Cr}_{23} \mathrm{C}_{6}$ enriched in Mo, which is confirmed by SAED patterns (Figure 4 (e) inset) revealing a lattice parameter of $10.63 \AA$ (binary $\mathrm{Cr}_{23} \mathrm{C}_{6}$ belongs to the cubic crystal structure with space group $F m \overline{3} m$ and lattice parameter $\mathrm{a}=10.65 \AA$ ). These carbides can cause $\mathrm{Cr}$ depletion in the matrix, lowering the solid solution strengthening effect [25,26], as it was observed after HIP treatment. In previous works on SLM of Hastelloy X, a similar phase was found after an annealing heat treatment. Tomus et al. suggested that it was $\mathrm{Cr}_{6} \mathrm{C}$ based on EDX data [16].
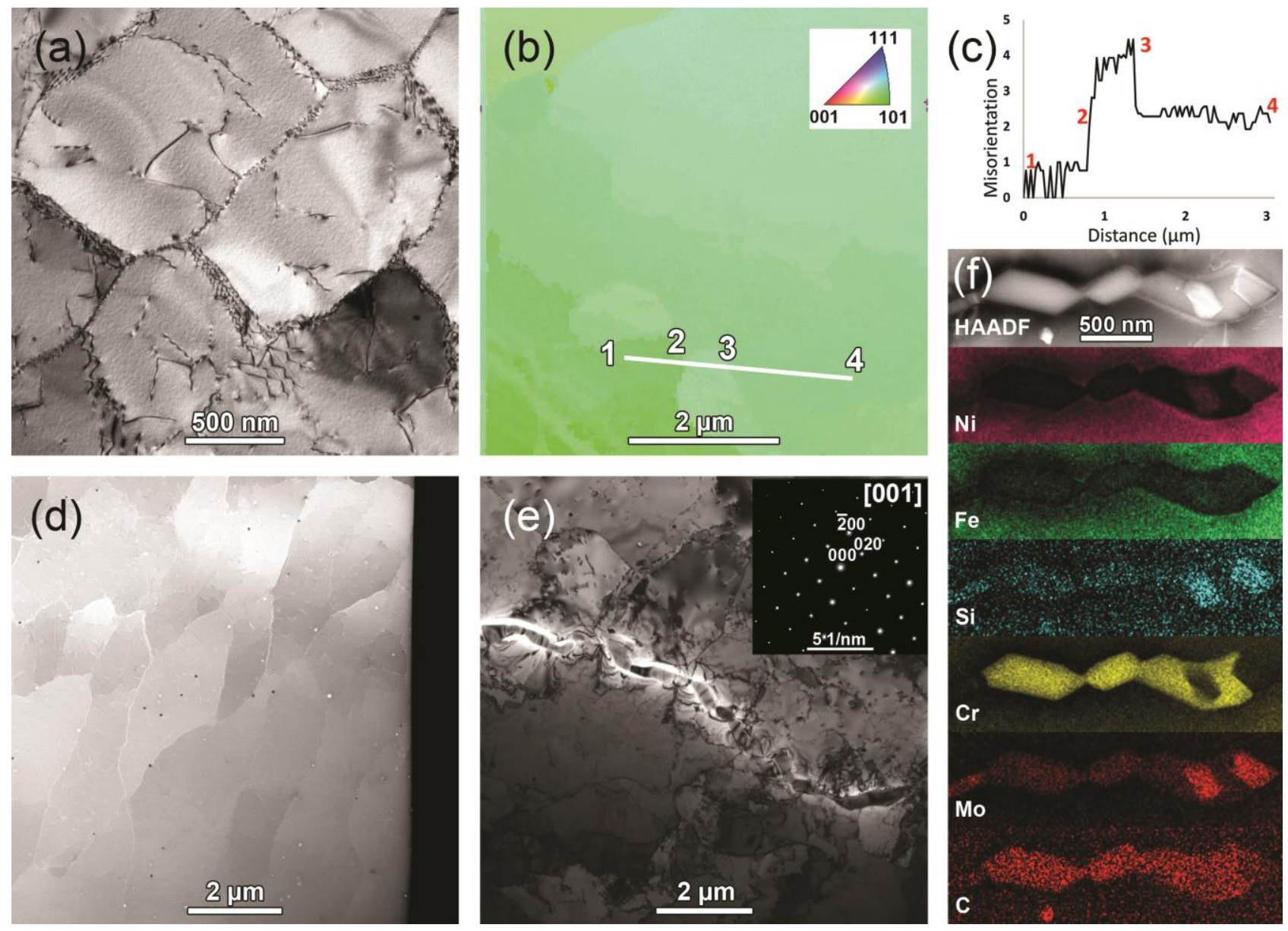

Figure 4 (a) BF-TEM image of a HIP sample taken in two-beam condition ([000] and [200] spots excited, same as Figure 2 (c)) showing sub-grains, (b) orientation map of a region of the HIP sample, (c) misorientation of some adjacent sub-grains along the line labeled in (b), (d) HAADF-STEM image showing precipitates randomly 
distributed in the sample, (e) BF-TEM image of chromium carbide based particles formed at a grain boundary, (f) HAADF-STEM and elemental maps of this phase.

\section{Conclusions}

This study has deepened the knowledge of the sub-grain structure of Hastelloy X produced by SLM and subsequent HIP post processing. A hierarchical microstructure was observed with grains of 50-100 $\mu \mathrm{m}$ in size to sub-grain cells of $0.5-1 \mu \mathrm{m}$ in diameter. Grains are typically defined as regions separated by misorientation angles $\geq 30^{\circ}$.

In the $\mathrm{AB}$ condition, the sub-structures that are present within a grain are dislocation cells, originating from a cellular solidification morphology, with misorientation angles $\leq 2 \pm 1^{\circ}$ that are decorated with high-density dislocation walls. It has been shown that after HIP the subgrain cells do not dissolve as suggested in literature. Instead, the dislocation cells turn into sub-grains, as observed by TEM. In ACOM-TEM, a misorientation of $4 \pm 1^{\circ}$ could still be observed, with a significantly reduced dislocation density. Especially the change in dislocation structure induced by the HIP treatment reduces the hardness of the material.

50-100 nm large precipitates enriched in $\mathrm{Cr}, \mathrm{Al}, \mathrm{Ti}, \mathrm{Mo}, \mathrm{Si}$ and $\mathrm{O}$ have been observed in both $\mathrm{AB}$ and HIP samples for the first time for SLM processed Hastelloy X. These precipitates are preferentially located within the dislocation walls in case of the AB sample. After HIP, $\mathrm{Cr}_{23} \mathrm{C}_{6}$ precipitates that are decorating a selected set of grain boundaries in a continuous fashion have been observed.

\section{Acknowledgement}

S.P. likes to thank the Flemish Science Foundation FWO for financial support under Project G.0366.15N. The authors acknowledge ENGIE Research and Technology Division for the use of the SLM280HL machine and financial support. This work was also made possible through the AUHA13009 grant "TopSPIN for TEM nanostatistics" of the Flemish HERCULES foundation.

\section{Data Availability}

The raw data required to reproduce these findings are available to download from [https://data.mendeley.com/submissions/evise/edit/5gd3fgrd4d?submission_id=S10445803(19)30389-4\&token=e08722f5-203b-47e5-a1f3-d18fde5f9082]. The processed data required to reproduce these findings are available to download from 
[https://data.mendeley.com/submissions/evise/edit/fxmbvyyg2y?submission_id=S10445803(19)30389-4\&token=e08722f5-203b-47e5-a1f3-d18fde5f9082].

\section{References}

[1] P. Kanagarajah, F. Brenne, T. Niendorf, H.J. Maier, Inconel 939 processed by selective laser melting: Effect of microstructure and temperature on the mechanical properties under static and cyclic loading, Materials Science and Engineering. A, Structural Materials: Properties, Microstructure and Processing. 588 (2013) 188-195. doi:10.1016/j.msea.2013.09.025.

[2] L. Thijs, K. Kempen, J.P. Kruth, J. Van Humbeeck, Fine-structured aluminium products with controllable texture by selective laser melting of pre-alloyed AlSi10Mg powder, Acta Materialia. 61 (2013) 1809-1819. doi:10.1016/j.actamat.2012.11.052.

[3] Y. Zhong, L. Liu, S. Wikman, D. Cui, Z. Shen, Intragranular cellular segregation network structure strengthening 316L stainless steel prepared by selective laser melting, Journal of Nuclear Materials. 470 (2016) 170-178. doi:10.1016/j.jnucmat.2015.12.034.

[4] F. Wang, Mechanical property study on rapid additive layer manufacture Hastelloy® X alloy by selective laser melting technology, International Journal of Advanced Manufacturing Technology. 58 (2012) 545-551. doi:10.1007/s00170-011-3423-2.

[5] N.J. Harrison, I. Todd, K. Mumtaz, Reduction of micro-cracking in nickel superalloys processed by Selective Laser Melting: A fundamental alloy design approach, Acta Materialia. 94 (2015) 59-68. doi:10.1016/j.actamat.2015.04.035.

[6] V.A. Popovich, E.V. Borisov, A.A. Popovich, V.Sh. Sufiiarov, D.V. Masaylo, L. Alzine, Functionally graded Inconel 718 processed by additive manufacturing: Crystallographic texture, anisotropy of microstructure and mechanical properties, Materials \& Design. 114 (2016) 441-449. doi:10.1016/j.matdes.2016.10.075.

[7] K.N. Amato, S.M. Gaytan, L.E. Murr, E. Martinez, P.W. Shindo, Microstructures and mechanical behavior of Inconel 718 fabricated by selective laser melting, Acta Materialia. 60 (2012) 2229-2239. doi:10.1016/j.actamat.2011.12.032.

[8] M. Cloots, P.J. Uggowitzer, K. Wegener, Investigations on the microstructure and crack formation of IN738LC samples processed by selective laser melting using Gaussian and doughnut profiles, Materials \& Design. $89 \quad$ (2016) 770-784. doi:10.1016/j.matdes.2015.10.027.

[9] V.D. Divya, R. Muñoz-Moreno, O.M.D.M. Messé, J.S. Barnard, S. Baker, T. Illston, H.J. Stone, Microstructure of selective laser melted CM247LC nickel-based superalloy and its evolution through heat treatment, Materials Characterization. 114 (2016) 6274. doi:10.1016/J.MATCHAR.2016.02.004.

[10] F. Brenne, A. Taube, M. Pröbstle, S. Neumeier, D. Schwarze, M. Schaper, T. Niendorf, Microstructural design of Ni-base alloys for high-temperature applications: impact of heat treatment on microstructure and mechanical properties after selective laser melting, Progress in Additive Manufacturing. 1 (2016) 141-151. doi:10.1007/s40964-016-00138.

[11] M. Cloots, K. Kunze, P.J. Uggowitzer, K. Wegener, Microstructural characteristics of the nickel-based alloy IN738LC and the cobalt-based alloy Mar-M509 produced by 
selective laser melting, Materials Science and Engineering: A. 658 (2016) 68-76. doi:10.1016/j.msea.2016.01.058.

[12] X. Wang, L.N. Carter, B. Pang, M.M. Attallah, M.H. Loretto, Microstructure and yield strength of SLM-fabricated CM247LC Ni-Superalloy, Acta Materialia. 128 (2017) 8795. doi:10.1016/J.ACTAMAT.2017.02.007.

[13] L. Liu, Q. Ding, Y. Zhong, J. Zou, J. Wu, Y.-L. Chiu, J. Li, Z. Zhang, Q. Yu, Z. Shen, Dislocation network in additive manufactured steel breaks strength-ductility trade-off, Materials Today. (2017). doi:10.1016/j.mattod.2017.11.004.

[14] O.M.D.M. Messé, R. Muñoz-Moreno, T. Illston, S. Baker, H.J. Stone, Metastable carbides and their impact on recrystallisation in IN738LC processed by selective laser melting, Additive $\quad$ Manufacturing. $22 \quad$ (2018) 394-404. doi:10.1016/J.ADDMA.2018.05.030.

[15] Haynes-International, Hastelloy $X$ alloy. (2017). http://haynesintl.com/alloys/alloyportfolio_/High-temperature-Alloys/HASTELLOY-X-alloy (erişim 09 Temmuz 2018).

[16] D. Tomus, Y. Tian, P.A. Rometsch, M. Heilmaier, X. Wu, Influence of post heat treatments on anisotropy of mechanical behaviour and microstructure of Hastelloy-X parts produced by selective laser melting, Materials Science and Engineering: A. 667 (2016) 42-53. doi:10.1016/J.MSEA.2016.04.086.

[17] G. Marchese, G. Basile, E. Bassini, A. Aversa, D. Ugues, P. Fino, S. Biamino, Study of the Microstructure and Cracking Mechanisms of Hastelloy X Produced by Laser Powder Bed Fusion, Materials. 11 (2018) 106. doi:10.3390/ma11010106.

[18] J.-C. Zhao, M. Larsen, V. Ravikumar, Phase precipitation and time-temperaturetransformation diagram of Hastelloy X, Materials Science and Engineering: A. 293 (2000) 112-119. doi:10.1016/S0921-5093(00)01049-2.

[19] O. Sanchez-Mata, X. Wang, J.A. Muñiz-Lerma, M.A. Shandiz, R. Gauvin, M. Brochu, Fabrication of crack-free nickel-based superalloy considered non-weldable during laser powder bed fusion, Materials. 11 (2018) 1-9. doi:10.3390/ma11081288.

[20] L.N. Carter, C. Martin, P.J. Withers, M.M. Attallah, The influence of the laser scan strategy on grain structure and cracking behaviour in SLM powder-bed fabricated nickel superalloy, Journal of Alloys and Compounds. 615 (2014) 338-347. doi:10.1016/j.jallcom.2014.06.172.

[21] K. Jin, Y.F. Gao, H. Bei, Intrinsic properties and strengthening mechanism of monocrystalline Ni-containing ternary concentrated solid solutions, Materials Science and Engineering: A. 695 (2017) 74-79. doi:10.1016/j.msea.2017.04.003.

[22] K. Saeidi, X. Gao, Y. Zhong, Z.J. Shen, Hardened austenite steel with columnar subgrain structure formed by laser melting, Materials Science and Engineering A. 625 (2015) 221-229. doi:10.1016/j.msea.2014.12.018.

[23] G. Marchese, E. Bassini, A. Aversa, M. Lombardi, D. Ugues, P. Fino, S. Biamino, Microstructural Evolution of Post-Processed Hastelloy X Alloy Fabricated by Laser Powder Bed Fusion, Materials (Basel, Switzerland). 12 (2019). doi:10.3390/ma12030486.

[24] M.L. Montero-Sistiaga, M. Godino-Martinez, K. Boschmans, J. Kruth, J. Van Humbeeck, K. Vanmeensel, Microstructure evolution of 316L produced by HP-SLM ( high power selective laser melting ), Additive Manufacturing. 23 (2018) 402-410. doi:10.1016/j.addma.2018.08.028. 
[25] J. Chander, Hardening mechanism and corrosion resistance of nickel-base alloys: A review, Canadian Metallurgical Quarterly. 3 (1964) 57-77. doi:10.1179/cmq.1964.3.1.57.

[26] R. Hu, G. Bai, J. Li, J. Zhang, T. Zhang, H. Fu, Precipitation behavior of grain boundary M 23C 6 and its effect on tensile properties of Ni-Cr-W based superalloy, Materials Science and Engineering A. 548 (2012) 83-88. doi:10.1016/j.msea.2012.03.092. 